\title{
Fractal Analysis of Root Architecture Responses of Saussurea Salsa to Different Habitats in Sugan Lake Wetland on the Northern Margin of Qinghai-Tibet Plateau
}

\section{Qun Li}

Northwest Normal University

Cheng-Zhang Zhao ( $\sim$ zhaocz1710@163.com )

Northwest Normal University https://orcid.org/0000-0002-8610-6599

Wen Jun

Northwest Normal University

Manping Kang

Northwest Normal University

Xiaoya Li

Northwest Normal University

\section{Research Article}

Keywords: Root architecture, Fractal dimension, Fractal abundance, Root-shoot ratio, Saussurea salsa, salt marshes

Posted Date: April 22nd, 2021

DOl: https://doi.org/10.21203/rs.3.rs-443185/v1

License: (c) (1) This work is licensed under a Creative Commons Attribution 4.0 International License.

Read Full License 


\section{Abstract}

\section{Aims}

The fractal structure is an important root architecture characteristic, which can reflect the plasticity mechanism and carbon consumption characteristics of root architecture in heterogeneous habitats. However, there are few studies on the root architecture of inland salt marsh plants from the perspective of fractal geometry.

\section{Methods}

This study according to the difference of the habitat conditions, setting plot I (the near water area, distance from the lakeshore, 50-200 m), plot II (the middle water area, distance from the lakeshore, 300$500 \mathrm{~m}$ ), plot III (the distance water area, distance from the lakeshore, 600-800 m) 3 test sample. The Saussurea salsa as the research object, the root geometric morphology traits and the root fractal structure of Saussurea salsa in the Sugan Lake wetland was studied in response to heterogeneous habitats.

\section{Results}

The results showed that there was a highly significant negative correlation $(p<0.01)$ between FD and FA of Saussurea salsa at plot I and plot III, meanwhile, there appeared a less significant negative correlation $(p<0.05)$ between FD and FA at plot II.

\section{Conclusions}

With the habitat changed from plot I to plot III, the Saussurea salsa tended to form an "intensive" root architecture with high fractal dimension (FD) and low fractal abundance (FA) in plot I. "Diffusive" root architecture with low FD and high FA tended to form in plot III. The root of Saussurea salsa had less branch and more inclined to increasing the soil volume of root expansion in the far water area.

\section{Introduction}

Wetlands play an irreplaceable role in maintaining global ecosystem security (Shao et al., 2012). The inland salt marsh is a type of wetland ecosystem that exhibits specific ecological and hydrological processes and a highly heterogeneous environment (Colmer, 2013). In arid and semi-arid areas, water loss as a result of evapotranspiration leads to an increase in salt concentration in soil components (Ivanova et al., 2019), and salinization becomes more and more serious. The soil salinity, water and soil bulk density, and other factors in salt marshes tend to show relative stability in time and space (Liu, et al., 
2016), which has a profound influence on patterns of plant community distribution, biomass distribution, and plant root morphological construction (Rossi et al., 2015).

Root is an important organ for plants to obtain underground resources and plays an important role in the process of plant growth. Root structure and function are closely related to the processes by which plants absorb water and nutrients from the soil (Pierret et al., 2016; Schmidt, 2014; Warren et al., 2015b; Yang et al., 2016). The root architecture system determines the ability of plants to absorb, transport water and nutrients uptake (Rubio et al. 2001, Wang et al.2019). Moreover, it is the first line of defense towards any abiotic or biotic stress (Bisht et al., 2019; Hu et al., 2018). Root system architecture includes geometric characteristics such as root length, root diameter, root forks and branch Angle. Besides, it also includes fractal structure, topology structure and spatial distribution (Lynch, 1995). Fractal geometry has been widely used in evaluating soil root structure and distribution (Dannowski and Block, 2005; Masi and Maranville, 1998; Tatsumi, 2001; Walk et al., 2004; Wang et al., 2009). The application of fractal theory to root research can deepen the understanding of root architecture. The fractal structure of roots reflects the spatial branching status (Walk et al., 2004), the complexity of plant roots and the ability of root expansion in the soil layer (Yang et al., 2015). Fractal dimension (FD) and fractal abundance (FA) are the important characteristics of root fractal structure. The FD of root reflects the spatial distribution form, branching ability and development degree of root (Walk et al., 2004), and directly affects the physiological function of root and the utilization ability of soil resources. The results have shown that the roots of plants with higher FD usually had complex branches, relatively developed lateral roots, and tended to grow horizontally (Cao, 2014), that is, they had better root foraging ability, and water and nutrient absorption efficiency under the input of unit carbon. The FA of roots is closely related to the distribution density of roots in the soil, the expansion range and the resource competition ability (Yang et al., 2009). The larger the FA, the higher the degree of taproot development, the larger the root distribution range, that is, the plant has stronger support, transport system and space occupation ability (Li et al., 2018; Ren et al., 2020). The relationship between FD and FA can reflect the plasticity and carbon consumption characteristics of plant root architecture to a large extent (Fitter et al., 2006, Song et al., 2015). At present, the studies on the relationship between FD and FA of plant roots mainly involved alpine grassland plant Melica przewalskyi (Song et al., 2015), the wetland plant Elymus Nutans (Li et al., 2019), and Agriophyllum squarrosum in the oasis desert ecotone (Ren et al., 2020). However, there are few studies on the root architecture of inland salt marsh plants from the perspective of fractal geometry.

The special ecohydrological process of land salt marsh makes the different pattern of soil resource allocation within wetland plant community (Liu, et al., 2016), which changes the carbon resource allocation pattern and root architecture strategy of each plant within the population. To improve the habitat adaptability and risk avoidance ability of the population, the geometric characteristics and fractal characteristics of plant roots will be adjusted with the environmental change, and the root nutrient absorption and transport system suitable for the habitat will be constructed to adapt to the complex and changeable habitat, thus improve the resistance and tolerance to the harsh habitat (Di Bella et al., 2014; Wang et al., 2018). Therefore, it is of great significance to explore the spatial differentiation of root 
architecture of halophytes in inland salt marsh wetlands from the perspective of root fractal structure to reveal the survival strategies of inland salt marsh plants in response to special environment.

Saussurea salsa is a halophyte belonging to Compositae and Saussurea genus. It is distributed in highaltitude saline grassland, Gobi Desert and lakeside areas, and is the main plant of inland salt marsh in Northwest China (Li et al., 2019). Studies on the correlation between reproductive allocation and altitude (Wang et al., 2012), leaf PSII photochemical efficiency and the adaptation mechanism of photosynthetic pigments to stressed habitats (Shi et al, 2012), the morphological and photosynthetic physiological characteristics of Saussurea salsa in response to flooding (Li et al., 2019) have also attracted attention. However, there are few studies to analyze the root architecture of Saussurea salsa in response to different habitats from the perspective of fractal geometry. Given this, this paper took Saussurea salsa, a typical halophytic plant in inland salt marsh, as the research object to explore the relationship between FD and FA of Saussurea salsa in different habitants. From the perspective of fractal geometry, this study tried to clarify, (1) What root system architecture strategies did Saussurea salsa have under different habitat conditions? (2) What are the relationships between root FD and FA of Saussurea salsa? What are the mechanisms of this relationship? The aim is to reveal the root architecture construction strategy of halophytes from the perspective of fractal geometry.

\section{Materials And Methods}

\subsection{Study sites and sampling}

The study site was located in Xiaosugan Lake Provincial Nature Reserve for Migratory Birds, Aksay County, Jiuquan City, Gansu Province, China. It is located in the Huahaizi Plateau Basin between Altyn Tagh Mountain, Danghe South Mountain and Saishiteng Mountain on the northern margin of Qaidam Basin on the Qinghai-Tibet Plateau $\left(39.22^{\circ}-39.35^{\circ} \mathrm{N}, 94.45^{\circ}-94.59^{\circ} \mathrm{E}\right.$ ) (Fig.1), at altitudes of 2807$2808 \mathrm{~m}$. The study area is characterized by an inland alpine and semi-arid climate, with an annual average temperature of $2.0^{\circ} \mathrm{C}$, an average annual precipitation of $77.6 \mathrm{~mm}$, an average annual evaporation of $1964.8 \mathrm{~mm}$, and an average frost-free period of 90 days, prevailing gale weather, high frequency of sandstorms, drying degree of 30 (Li et al., 2019).

The Sugan Lake water system is an independent water system at the central and northwest end of the Qaidam inner water system. It originates from the Da and Xiao Haerteng Rivers in the Nanshan of the Danghe River, and flows underground through the mountain passes, flows into the Da and Xiao Sugan Lakes in the Haizi Basin, and then flows into the Da and Xiao Sugan Lakes. Finally, it is consumed by lake evaporation and evapotranspiration in the spring overflow zone. According to the classification standard of Chinese soil classification system in 1992, the main soil types in the study area are meadow soil, meadow swamp soil and saline-alkali soil. The dominant plant species are Saussurea salsa, Leymus secalinus, Phragmites australis, Glaux maritima, Triglochin palustre, Triglochin maritimum, Suaeda glauca, Blysmus sinocompressus, and Salicornia europaea. (Li et al., 2019) 
From 15 to 27 August 2020, based on the field investigation, an area with relatively representative habitat gradient change was selected along the northwest shore of Xiaosugan Lake in the direction of the vertical water area. A rectangular transect (800 $\mathrm{m}$ in length $\times 200 \mathrm{~m}$ in width) was arranged as the study sample. The plant community in this transect was dominated by Saussurea salsa, accompanied by plants such as Leymus secalinus and Salicornia europaea.

First, the groundwater depth was measured (the groundwater was dug with a shovel at intervals of $50 \mathrm{~m}$ from near the lakeshore in each transect, and measured after the water level stabilized). Then, based on the distance from the lakeshore and the variation of groundwater depth, the transect was divided into three plots (Plot I, Plot II and Plot III, Fig.1). They were as follows, 1) Plot I, The near water area, 0-200 m from the water body, groundwater depth $0.30-0.50 \mathrm{~m}$. There was no accumulation of salt and alkali in the soil surface, and the soil moisture was saturated almost all the year round. The main plants in this region are Triglochin maritimum, Glaux maritima, Saussurea salsa and so on. 2) Plot II, the middle water area, 300-500 m away from the water body, groundwater depth 0.50-1.00 m. This area was seasonally flooded and soil water is seasonally saturated. The accumulation of salt and alkali in the soil surface was stronger than Plot I. The vegetation was patchlike, with Saussurea salsa, Glaux maritima and Leymus secalinus growing together. 3) Plot III, the far water area, 600-800 $\mathrm{m}$ from the water body, groundwater depth 1.00-1.50 m. The accumulation of salt and alkali in the soil surface was strongest. Vegetation was distributed in aggregated patches with low height and high density. The main plants were Saussurea salsa and Leymus secalinus.

Third, based on this gradient of the Saussurea salsa population in the sample, six $1 \mathrm{~m} \times 1 \mathrm{~m}$ quadrats were established in each plot, for an overall total of 18 quadrats. Fourth, the community traits (height and coverage) were determined. Fifth, 6 well-growing Saussurea salsa plants were selected from each plot. After measuring the height of the plants, the aboveground parts were cut off and put into numbered envelopes. The root of each Saussurea salsa was completely dug after measuring the root depth and branch angle by using the trench method and the whole root excavation method. The root was placed with a mesh screen (aperture $=0.25 \mathrm{~mm}$ ), and the adjacent water source was searched to clean the soil and debris attached to the root. The soil was put into the numbered self-sealing bag respectively, and the root was brought back to the laboratory together with the aboveground part to measure the biomass and other traits. Finally, the aboveground parts of all plants in each plot were cut and transported to the laboratory. The aboveground biomass of each plot was measured after drying in an oven at $80^{\circ} \mathrm{C}$ for 48 h.

2.21 Measurement of root morphological characteristics and organs biomass of Saussurea salsa

In the laboratory, Saussurea salsa roots were put on the root disk of a root scanner with a small amount of water to make it spread out. After scanning, the root was stored in a graphic file to the computer, and the average diameter, root length and root forks (RF) of the root were measured with WIN-Rhizo (Pro 5.0) software (Regent In-struments, Canada). RF refers to the number of forks per unit root length. Within the same unit length, the higher the number of forks, the stronger the ability of the root to absorb nutrients or 
water. The formula is, RF (No. $\left.\mathrm{cm}^{-1}\right)=$ The number of RF (No.)/ root length (cm) (Liu et al., 2010). Then, the root and leaf parts of Saussurea salsa were put into the numbered envelope bags and placed in the oven. They were measured after drying in an oven at $80^{\circ} \mathrm{C}$ for $48 \mathrm{~h}$. Root-shoot ratio $=$ underground biomass/aboveground biomass, and specific root length $(\mathrm{cm} / \mathrm{g})=$ root length $(\mathrm{cm}) /$ root biomass $(\mathrm{g})$.

\subsubsection{Measurement of fractal characteristics of Saussurea Salsa Roots}

The roots of Saussurea salsa were analyzed with WIN-Rhizo (Pro 5.0) software (Regent Instrumentation, Canada), obtaining squares with side length of $r$ and the number of squares cut by roots in root distribution maps of each plot. As the square length $r$ decreases gradually, the $\mathrm{Nr}$ cut by the root system increases gradually. After obtaining the corresponding $\mathrm{Nr}$ values at different levels of $r$, the graph was drawn with Igr and IgNr as abscissa and ordinate respectively. The equation of the regression line is,

$$
l g^{N r}=-F D l g^{r}+l g^{k}
$$

The negative number of the slope of the regression line is the fractal dimension (FD), and lgK is the fractal abundance (FA) (Ketipearachchi and Tatsumi, 2000). When $r=1$, the FA has a maximum value, IgNr $=\operatorname{lgK}, F D=0$, that is, there is no branching, which does not actually exist.

\subsubsection{Measurement of soil moisture content, soil bulk density, soil salinity and $\mathrm{pH}$}

In the wetland community survey, soil samples were randomly collected of the $1 \mathrm{~m} \times 1 \mathrm{~m} \times 0.5 \mathrm{~m}$ (length $\times$ width $\times$ depth $)$ soil profile using a ring knife $\left(200 \mathrm{~cm}^{3}\right)$. Five soil layers each of $10 \mathrm{~cm}$ depth were collected, with three replicates per layer. The replicate soil samples were mixed while fresh, then ovendried at $105^{\circ} \mathrm{C}$ for $12 \mathrm{~h}$. The soil moisture content (SMC) and soil bulk density (SBD) were calculated for each soil layer.

The salt content of the soil samples was measured using the EC method. A sample ( $10 \mathrm{~g})$ of air-dried soil sieved with $2 \mathrm{~mm}$ mesh was weighed at room temperature, then $50 \mathrm{~mL} \mathrm{CO}$-free distilled water was added (water: soil mass 5:1, v/w). The leachate was collected and placed in an oscillator for $5 \mathrm{~min}$. Using a vacuum filtration system, the suspended soil slurry was slowly poured into the funnel until filtration was completed. The filtrate was poured into conical flasks for later use (Li et al., 2019). A portable conductivity meter (DDS-11C, Shanghai Lei Magnetic Instrument Factory, Shanghai, China) and portable soil pH meter (ST3100, Ohaus Instruments Co., Ltd, Shanghai, China) were used to measure the EC and $\mathrm{pH}$ of the leachate, respectively, with three replicates per sample, and the average was calculated.

\subsection{Statistical analysis}

Microsoft Excel 2019 was used to organize all the original data of the experiment, and the root shoot ratio, stem mass ratio, leaf mass ratio and root mass ratio of various Saussurea Salsa were calculated respectively. Secondly, the correlation between geometric characteristics of roots and fractal structural parameters of Saussurea Salsa under habitat gradient were analyzed in the R 4.0.2 software. Then, the 
experimental data of FD and FA of Saussurea Salsa were converted by log 10 to make them conform to normal distribution. At last, the relationship between FD and FA of roots of Saussurea Salsa was analyzed by linear regression analysis. Plot with origin 2016 and SigmaPlot 10.0 software. The mean and standard error (SE) of five replicates were obtained for each measurement.

Table 1 Common parameters and their abbreviations

\begin{tabular}{|lll|}
\hline Parameter & Abbreviations & Units \\
\hline Soil moisture content & $S M C$ & $\%$ \\
\hline Soil electrical conductivity & $E C$ & $\mathrm{~ms}^{-\mathrm{cm}^{-1}}$ \\
\hline Soil bulk density & $S B D$ & $\mathrm{~g} / \mathrm{cm}^{3}$ \\
\hline Aboveground biomass & $A B$ & $\mathrm{~g} \cdot \mathrm{m}^{-2}$ \\
\hline Average height & $A H$ & $\mathrm{~cm}$ \\
\hline Density & $D$ & $\mathrm{strain} \cdot \mathrm{m}^{-2}$ \\
\hline Coverage & $C$ & $\%$ \\
\hline Root depth & $R d e p$ & $\mathrm{~cm}$ \\
\hline Stem biomass & $S M$ & $\mathrm{~g}$ \\
\hline Leaf biomass & $L M$ & $\mathrm{~g}$ \\
\hline Root biomass & $R M$ & $\mathrm{~g}$ \\
\hline Root surface area & $R S A$ & $\mathrm{~cm}$ \\
\hline Total Root length & $T R L$ & $\mathrm{~cm}$ \\
\hline Root average diameter & $R A D$ & $\mathrm{~mm}$ \\
\hline Specific root length & $S R L$ & $\mathrm{~cm} / \mathrm{g}$ \\
\hline Root forks & $R F$ & No./cm \\
\hline Root branch angle & $R B A$ & $\circ$ \\
\hline Fractal dimension & $F D$ & $\mathrm{No} \mathrm{dimension}$ \\
\hline Fractal abundance & $F A$ & $\mathrm{No} \mathrm{dimension}$ \\
\hline Root-shoot ratio & $R S R$ & Nimension \\
\hline
\end{tabular}


3.1 Soil characteristics of each habitat community

With the condition of the habitats changing from plot I to plot III, the SMC, $\mathrm{pH}$ and SBD displayed decreasing trends, and decreased by $40.70 \%, 5.23 \%$ and $23.44 \%$, respectively. The soil EC showed increasing trends, and increased by 4.35 times, from plot I to plot III. (Fig.2, S Table 1)

\subsection{Biological characteristics of each habitat community}

With the condition of the habitats changing from plot I to plot III, the average community height, aboveground biomass and coverage exhibited decreasing trends, and decreased by $40.70 \%, 71.00 \%$ and $37.36 \%$, respectively. Moreover, the main species gradually changed from Saussurea salsa, Triglochin maritimum and Glaux maritima to Saussurea salsa and Leymus secalinus (Table 2).

Table 2 Biological characteristics of wetland community in different plot (mean $\pm S E$ )

\begin{tabular}{|c|c|c|c|c|}
\hline Plot & $\mathrm{AH}(\mathrm{cm})$ & $A B\left(g \cdot m^{-2}\right)$ & $\mathrm{C}(\%)$ & Main Species \\
\hline 1 & $\begin{array}{l}20.76 \pm \\
1.91 \mathrm{a}\end{array}$ & $\begin{array}{l}279.00 \pm \\
10.54 a\end{array}$ & $\begin{array}{l}91 \pm \\
1.52 \mathrm{a}\end{array}$ & $\begin{array}{l}\text { Saussurea salsa Triglochin maritimum } \square \text { Salicornia } \\
\text { europaea》 Glaux maritima }\end{array}$ \\
\hline II & $\begin{array}{l}14.84 \pm \\
2.77 \mathrm{~b}\end{array}$ & $\begin{array}{l}151.97 \pm \\
8.34 \mathrm{~b}\end{array}$ & $\begin{array}{l}81 \pm \\
1.62 \mathrm{~b}\end{array}$ & $\begin{array}{l}\text { Saussurea salsa } \text { Leymus secalinus } \square \text { Salicornia } \\
\text { europaea }\end{array}$ \\
\hline III & $\begin{array}{l}12.31 \pm \\
3.39 \mathrm{c}\end{array}$ & $\begin{array}{l}80.89 \pm \\
1.95 \mathrm{c}\end{array}$ & $\begin{array}{l}57 \pm \\
2.52 \mathrm{c}\end{array}$ & Saussurea salsa $[$ Leymus secalinus \\
\hline
\end{tabular}

\subsection{The population characteristics of Saussurea salsa}

With the change in habitat from plot I to plot III, the average height of the Saussurea salsa population increased firstly and then decreased, and ultimately decreased by $43.40 \%$, the density showed decreasing trends, and decreased $80.85 \%$, while the RSR and root depth displayed increasing trends gradually, and increased by 1.70 and 1.05 times, respectively (Fig.3, S Table 2).

3.4 Comparisons of stem biomass fraction, leaf biomass fraction and root biomass fraction under different habitats of Saussurea salsa

Under different habitat conditions, the biomass proportion of organs in Saussurea salsa was significantly different $(P<0.05$, Fig. 4). With the change of habitat from plot I to plot III, the Psb and Plb of Saussurea salsa significantly decreased $(P<0.05)$, decreased from $33.17 \%$ and $37.29 \%$ of plot I to $29.56 \%$ and 
$18.9 \%$ of plot III, respectively. The Prb was significantly increased $(P>0.05)$, increased from $29.54 \%$ of plot I to $51.54 \%$ of plot III.

3.5 The main morphological characteristics of Saussurea salsa in each habitat

With the change in habitat from plot I to plot III, the RSA, RAD, RBA and FA showed increasing trends, and increased by $1.13,0.84,0.60$ and 0.13 times, respectively (Table 3 ). The TRL, SRL, RF and FD exhibited decreasing trends, and increased by $17.13 \%, 50.52 \%, 55.36 \%$ and $17.05 \%$, respectively.

Table 3 The main root geometric characteristics and fractal structural parameters of Saussurea salsa in each plot (mean $\pm \mathrm{SE})$

\begin{tabular}{|c|c|c|c|}
\hline Plot & I & $\|$ & III \\
\hline TRL (cm) & $186.45 \pm 7.89 a$ & $167.65 \pm 5.13 b$ & $154.51 \pm 4.93 c$ \\
\hline $\mathrm{RSA}\left(\mathrm{cm}^{2}\right)$ & $40.53 \pm 0.36 c$ & $66.13 \pm 1.56 b$ & $86.51 \pm 3.93 a$ \\
\hline $\mathrm{RAD}(\mathrm{mm})$ & $0.93 \pm 0.05 c$ & $1.36 \pm 0.08 b$ & $1.71 \pm 0.08 a$ \\
\hline $\mathrm{RF}$ (No./cm) & $12.41 \pm 0.24 a$ & $8.55 \pm 0.23 b$ & $5.54 \pm 0.30 c$ \\
\hline $\operatorname{RBA}\left({ }^{\circ}\right)$ & $40.01 \pm 1.48 c$ & $51.55 \pm 1.58 b$ & $64.00 \pm 1.54 a$ \\
\hline SRL (cm/g) & $208.73 \pm 1.66 a$ & $117.63 \pm 1.46 b$ & $103.28 \pm 1.65 c$ \\
\hline FD & $1.76 \pm 0.04 a$ & $1.59 \pm 0.03 b$ & $1.46 \pm 0.02 c$ \\
\hline FA & $2.98 \pm 0.13 c$ & $3.13 \pm 0.17 b$ & $3.38 \pm 0.13 a$ \\
\hline
\end{tabular}

\subsection{The correlation analysis of root characteristics of Saussurea salsa}

The correlation analysis of root characteristics of Saussurea salsa was showed in Fig.5 and S Table 3. It was shown that a highly significant negative correlation $(p<0.01)$ between FD and FA, RSA, RAD, and RBA, and between TRL and RAD, RBA, and between RSA, RAD and RF, SRL, and between RF and RBA, as well as a highly significant negative correlation between RBA and SRL in all of the three plots. While a highly significant positive correlation was observed $(p<0.01)$ between $\mathrm{FD}$, TRL and RF, SRL, and between RSA and RAD, RBA, and between RAD and RBA, meanwhile, a highly significant positive correlation between RF and SRL in three habitats. Moreover, a less significant negative correlation was observed ( $p<$ $0.05)$ between TRL and RSA, while a less significant positive correlation was observed $(p<0.05)$ between FA and RBA.

3.6 The correlation between fractal dimension and fractal abundance of Saussurea salsa. 
To further analyze the trade-off relationship between Saussurea salsa FD and FA under three habitat conditions, linear regression analysis was performed on FD and FA. The trade-off relationship between FD and FA in Saussurea salsa in different habitats was shown in Fig 6. The linear regression analysis showed that there was a highly significant negative correlation between FD and FA in both near water and far water areas $(P<0.01, \mathrm{I}$ and III), and a less significant negative correlation in the middle water area $(P<$ 0.05 , II). On the habitat gradient, there were opposite trends between FD and FA in root of Saussurea salsa. From plot I to plot III, the standardized major axis (SMA) slope of the regression equation between FD and FA increased gradually $(P<0.05)$. The absolute value of the SMA slope in each habitat was significantly less than 1 . It indicated that the decreasing rate of root FD was less than the increasing rate of FA from the near water area to the far water region, and Saussurea salsa was more inclined to increase the soil volume of root expansion.

\section{Discussion}

Root architecture system is the first line of defense towards any abiotic or biotic stress (Bisht et al., 2019; Hu et al., 2018), and determines the ability of plants to obtain nutrients and water (Rubio et al. 2001, Wang et al.2019). Fractal structure is an important characteristic of root architecture, which directly reflects the spatial expansion ability and resource utilization efficiency of plant roots. In this study, we found that with the change of habitat conditions from the near water area to the far water area, the root FD of Saussurea salsa gradually decreased, and the FA gradually increased. There was a trade-off between the FD and the FA.

\subsection{The correlation between FD and FA of Saussurea salsa in the Near water area}

The root is the major organ for anchorage, acquisition of water and nutrients or carbon storage (Van et al., 2016). Root's ability to obtain soil resources essential for growth and survival determines a plant's yield and is highly influenced by competition with other plants' roots (Cahill and McNickle, 2011). FD and FA are important characteristics of root fractal structure, and the FD of root reflects the spatial distribution morphology, branching ability and development degree of root (Walk et al., 2004). The study area belongs to the alpine arid wetland ecosystem on the northern margin of the Qinghai-Tibet Plateau, with low temperature all year round, which limits the growth and reproduction of plants. In the near water area, the height, coverage and aboveground biomass of the plant community were the largest, and the competition of resources within the community was fierce (Table 2). SMC was sufficient, SBD and pH were maximum, and EC was minimum (Fig.2, S Table 1). The population density of Saussurea salsa was the highest and its height was low (Fig.3, S Table 2) in this habitat. To avoid shading from adjacent larger plants and obtain more light resources, more biomass was used for the growth of stems and leaves above ground (Fig.4). In the case of limited underground investment, the "intensive" root architecture with minimum root-shoot ratio, root depth and root branch angle (RBA) (Fig.3, S Table 2, Table 3) was selected. The reason are as follows, first, Saussurea salsa chose to inhibit the vertical expansion of roots, which were concentrated in the $0-15 \mathrm{~cm}$ soil layer. In this habitat, the RSA was the smallest, while the total root length, RF and SRL were the largest, which reduced the FA of the root (Table 3). In this way, can 
Saussurea salsa not only reduce the spatial distribution range of roots, and decrease the resource input of root support and transmission system, but also reduce the resource competition intensity between roots and shorten the water transport distance of roots (Li et al., 2019). Moreover, it helps to optimize the relationship between root water and nutrient absorption capacity and its carbohydrate consumption level (Ma, 2008). For another, under the condition of sufficient soil moisture, minimum RSR and limited underground biomass, Saussurea salsa used more biomass to increase lateral roots, which reduced the average root diameter and increased the FD and root forks (RF) (Table 3). Compared with competitors, higher root FD not only improves the adsorption capacity and resource extraction capacity of plant roots to the soil but also improves the nutrient absorption efficiency of roots (Forde and Lorenzo, 2001; Hodge, 2004), which guarantees high interspecific competition ability of plants and the normal growth of plants (Dong, 1996). Therefore, we observed a highly significant negative correlation between FD and FA of Saussurea salsa in the near water area $(P<0.01$, Fig.6). Saussurea salsa's "intensive" root architecture by increasing FD and decreasing FA is a life-history strategy to improve population competitiveness and resource acquisition efficiency, which reflects the ecological adaptation mechanism of inland salt marsh plants to harsh habitats through root morphology and fractal structure. This conclusion is consistent with the conclusion of relevant scholars that "FD can reflect root branching, and plants with larger FD have stronger root branching ability (Song et al., 2015; Shan et al., 2012).

\subsection{The correlation between FD and FA of Saussurea salsa in the Far water area}

Optimal allocation theory (OPT) suggests that plants can alleviate stress levels through allocating biomass to the organs that acquire the most limiting resources to increase resource uptake capacity (Freschet et al., 2018; Mccarthy and Enquist, 2007). 'Root mass fraction' depicts the relative investment of biomass to specific belowground parts and therefore is a key trait in determining plant performance (Poorter et al., 2012; Wilson, 1988). Compared with plot I and plot II, in the far water area, plant community height, $A B$ and $C$ were the lowest (Table 2), and interspecific competition was the least. SBD, $\mathrm{pH}$ and SMC were the smallest, while EC was the highest (Fig.2, S Table 1) at plot III. This habitat was not conducive to plant growth. Saussurea salsa faces the dual stress of water and salt, with minimum height and density (Fig.3) in this habitat. To improve the ability to obtain water resources, Saussurea Salsa increased the input of vertical root resources and limited the input of above-ground resources. Driven by the foraging effect, the "diffusive" root architecture with the largest RSR, root depth and RBA was formed (Fig.3, Table 3, S Table 2). The reasons are as follows, first, increased the FA not only enhanced the support and transport function of roots, expanded the distribution range and the soil space occupied by unit roots (Li et al., 2019), but also improved the absorption range of soil water and nutrients by roots of Saussurea salsa, and alleviated the soil water stress in the remote water area. For another, under limited resources, Saussurea salsa reduced the biomass allocation of stems and leaves on the ground, and increased the biomass allocation of roots. The RMF, TRL, RSA and RD were the largest (Fig.4), and SRL was small in the remote water area (Table 3 ). These results are consistent with the relevant conclusions that the increase of soil salt concentration will reduce the SRL and increase the root diameter (Tan et al., 2020). Under certain underground biomass, reducing the RF and FD, increasing the root FA (Table 3), which was conducive to keeping Saussurea salsa away from the environment with high salt and low 
moisture content in the surface soil, and expanding the utilization space for deep soil moisture and nutrients. This conclusion is consistent with the conclusion of relevant scholars that 'increasing the FA of roots can increase the space for root expansion and enhance the ability of root to absorb soil resources in arid regions' (Shan et al., 2013). Therefore, there was a highly significant negative correlation between the root FD and FA of Saussurea salsa in this habitat $(P<0.01$, Fig.6) and Saussurea salsa was more inclined to increase the soil volume of root expansion in the far water area. Saussurea salsa in inland alpine and arid salt marsh wetland construct a "diffusive" root architecture by increasing FA and decreasing FD, which is an ecological adaptation mechanism to the dual water and salt stress.

\subsection{The correlation between FD and FA of Saussurea salsa in the middle water area}

The pattern of resource allocation at plant component level is the result of long-term adaptation of plants to habitat environment. Plant root is an important organ for plants to obtain underground resources. Its structure and function are closely related to the process of controlling plants' absorption of water and nutrients from the soil, and the assimilation, distribution and release of carbon into the soil (Pierret et al., 2016; Schmidt, 2014; Warren et al., 2014; Yang et al., 2016). The height, $A B$ and $C$ of the plant community in plot II were all between plot I and plot III (Table 2), and the interspecific competition was weaker compared with Plot I. SMC, pH and SBD were lower than those in plot I, and EC value was significantly higher than that in plot I (Fig.2, S Table 1). This habitat was benefit to plant growth, the population height of Saussurea salsa was the highest, and its density, RSR and root depth were all between plot II and plot III (Fig.3, S Table 2). To adapt to the existing living environment, Saussurea salsa coordinated changes in root geometric morphology and fractal structure by balancing biomass allocation between above-ground stems and leaves and underground roots, reasonably allocating the investment of limited resources in root support, transport and absorption structure, and making its root FD and FA between plot I and plot III. Therefore, plot II was a region in which the root FD gradually decreased and the FA gradually increased of Saussurea salsa, and there was a significant negative correlation between the FD and the FA $(P<0.05$, Fig. 6). The root architecture of Saussurea salsa in this habitat was a transitional type from 'intensive' to 'diffusive' root architecture. Under different habitat conditions, Saussurea Salsa reasonably balance the root resources allocation patterns on the FD and FA, which reflects the resource investment trade-off mechanism of root architecture construction and the survival strategy of inland salt marsh plants to adapt the harsh habitats.

\section{Declarations}

The manuscript has been approved by all authors. I would like to declare on behalf of my co-authors that the work described was original research that has not been published previously, and not under consideration for publication elsewhere, in whole or in part. All the authors listed have approved the manuscript that is enclosed.

\section{Funding}


This work was supported, in part, National natural science foundation of China (Grant NO. 41461013 and NO. 41861009).

\section{Competing Interests}

The authors declare that there are no conflicts of interest.

\section{Availability of data and material}

All study-related data has been provided in the supporting information

\section{Author's contributions}

Qun Li (QL), Cheng Z Zhao (CZZ), Wen Jun (WJ), Man P Kang (MPK) and Xiao Y Li (XYL) conceived and designed the experiments. QL performed the experiments, analyzed the data and drafted the manuscript. CZZ support in the funding acquisition, resources and critical revision of the article. QL, WJ, MPK and $\mathrm{XYL}$ undertook the investigation and contributed the methodology. All authors reviewed and approved the final manuscript.

\section{Acknowledgements}

This work was supported, in part, National natural science foundation of China (Grant NO. 41461013 and NO. 41861009). We thank Robert McKenzie, PhD, from Liwen Bianji, Edanz Group China (www.liwenbianji.cn/ac), for editing the English text of a draft of this manuscript. Besides, we are very grateful to Xue Bai, Min Ma, DaWei Wang, Yufang Wang, Yurui Tang, Tingting Zhao, Hongxia Zeng, Xuqian Bai and Zhiwei Zhang for their assistance in the field and laboratory work.

\section{Conclusion}

The plasticity of plant root architecture changes with the environmental difference of the resources needed for its survival. The differences in the root geometric morphology traits and the fractal structure of plant roots in heterogeneous environments reflect the survival strategies of plants in heterogeneous habitats. In this study, it was found that Saussurea salsa tended to increase the FD and decrease the FA of root in the near water region. Therefore, the 'intensive' root architecture with high soil resource utilization efficiency was an effective way to improve the interspecific competition ability of Saussurea salsa. In the distant water region, Saussurea salsa tended to reduce the FD, increase the FA, and construct a 'diffusive' root architecture with high expansion ability, which was the survival strategy of Saussurea salsa in response to water and salt stress. Taken together, these results indicate that the plants in inland salt marsh wetland can effectively balance the allocation of root and shoot biomass to achieve the coevolution of root geometry and fractal structure to maintain the ecological adaptation strategy of survival, growth and reproduction. 
Based on the analysis of biomass allocation and root geometric parameters, this study investigated the responses of root geometric morphology traits and fractal structure to different habitats. Root topological structure and other organ traits also play a crucial role in coping with differences in soil salinity, salt ions, soil organic matter and nutrients, which need to be further explored and studied.

\section{References}

1. Bisht N, Tiwari S, Singh PC et al (2019) A multifaceted rhizobacterium Paenibacillus lentimorbus alleviates nutrient deficiency-induced stress in Cicer arietinum L. Microbiol Res 223: 110-119. https://doi.org/ 10.1016/j.micres.2019.04.007

2. Colmer TD, Colmer TD, Pedersen 0 et al (2013) Oxygen dynamics in a salt-marsh soil and in Suaeda maritima during tidal submergence. Environmental and Experimental Botany, 92: 73-82. https://doi.org/10.1016/j.envexpbot.2012.07.002

3. Cao YS (2014) The study of influence factors of soil Reinforcement mechanism by Pinus tabuliformis root in north mountain of Hebei Province [D]. Beijing Forestry University

4. Cahill JF, McNickle GG (2011) The Behavioral Ecology of Nutrient Foraging by Plants. Annual Review of Ecology. Evolution Systematics 42(1):289-311. https://doi.org/10.1146/annurev-ecolsys-102710145006

5. Dannowski M, Block A (2005) Fractal geometry and root system structures of heterogeneous plant communities. Plant Soil 272(1-2):61. https://doi.org/10.1007/s11104-004-3981-2

6. Di Bella CE, Striker GG, Escaray FJ et al (2014) Saline tidal flooding effects on Spartina densiflora plants from different positions of the salt marsh. Diversities and similarities on growth, anatomical and physiological responses. Environmental and Experimental Botany, 102: 27-36. http://dx.doi.org/10.1016/j.envexpbot.2014.02.009

7. Dong M (1996) Clonal growth in plants in relation to resource heterogeneity foraging behavior. Acta Botanica Sinica 38(10):828-835. https://doi.org/ CNKI:SUN:ZWXB.0.1996-10-011

8. Forde B, Lorenzo H (2001) The nutritional control of root development. Plant Soil 232:51-68. https://doi.org/10.1023/a:1010329902165

9. Freschet GT, Violle C, Bourget MY et al (2018) Allocation, morphology, physiology, architecture: the multiple facets of plant above- and below-ground responses to resource stress. New Phytol 219:1338-1352. https://doi.org/10.1111/nph.15225

10. Fitter AH, Sticklabd TR (2006) Architectural analysis of plantroot systems 2. Influence of nutrient supply on architecture in contrasting plant species. New Phytol 121(2):243-248. https://doi.org/10.1111/j.1469-8137.1991.tb00019.x

11. Hu L, Xie Y, Fan S et al (2018) Comparative analysis of root transcriptome profiles between droughttolerant and susceptible wheat genotypes in response to water stress. Plant Sci 272:276-293. https://doi.org/10.1016/j.plantsci.2018.03.036 
12. Hodge A (2004) The plastic plant: root responses to heterogeneous supplies of nutrients. New Phytol 162:9-24. https://doi.org/10.1111/j.1469-8137.2004.01015.x

13. Ivanova K, Geneva M, Anev S et al (2019) Effect of soil salinity on morphology and gas exchange of two Paulownia hybrids. Agroforestry Systems, 93: 929-935. https://doi.org /10.1007/s10457-0180186-x

14. Ketipearachchi KW, Tatsumi J (2015) Local fractal dimensions and multifractal analysis of the root system of legumes. Plant Production Science 3(3):289-295. https://doi.org/10.1626/pps.3.289

15. Liu L, An SQ, Zhi YB et al (2016) Effects of different sediment type and burial depth on growth traits and biomass accumulation of Spartina anglica. Biodiversity Science, 24 (11): 1279-1287. https://doi.org/ 10.17520/biods.2016024

16. Liu J, Xiang WH, Xu X et al (2010) Analysis of architecture and functions of fine roots of five subtropical tree species in Huitong, Hunan Province, China. Chinese Journal of Plant Ecology, 34: 938-945. https://doi.org/ 10.3773/j.issn.1005-264x.2010.08.006

17. Lynch J (1995) Root architecture and plant productivity. Plant Physiol, 109(1): 7-13. https://doi.org/ $10.2307 / 4276771$

18. LI Q, Zhao CZ, Wang JW et al (2019) Morphological and photosynthetic physiological characteristics of Saussurea salsa in response to flooding in salt marshes of Xiao Sugan Lake, Gansu, China. Chin J Plant Ecol 43(8):685-696. https://doi.org/10.17521/cjpe.2019.0132

19. Li XP, Zhao CZ, Ren Y et al (2018) Fractal root systems of Elymus nutans under different density conditions in Gahai Wetland. Acta Ecologica Sinica, 2018, 38(4):1176-1182. https://doi.org/ $10.5846 /$ stxb201701200172

20. Masi CEA, Maranville JW (1998) Evaluation of sorghum root branching using fractals. J Agric Sci 131:259-265. https://doi.org/10.1017/S0021859698005826

21. Ma J (2008) Distribution Characteristics of Root System and Fractal Characters of Fruit Trees in Fruit-Wheat Intercropping in Hillside Fields on Loess Platea [D]. Beijing Forestry University

22. Poorter H, Niklas KJ, Reich PB et al (2012) Biomass allocation to leaves, stems and roots: metaanalyses of interspecific variation and environmental control. New Phytol 193: 30-50. https://doi.org/ 10.1111/j.1469-8137.2011.03952.x

23. Pierret A, Maeght JL, Clément $C$ et al (2016) Understanding deep roots and their functions in ecosystems: an advocacy for more unconventional research. Ann Bot 118(4): 621-635. https://doi.org /10.1093/aob/mcw130

24. Paungfoo-Lonhienne C, Lonhienne TGA, Yeoh YK et al (2013) A new species of Burkholderia isolated from sugarcane roots promotes plant growth. Microb Biotechnol 7(2): 142-154. https://doi.org /10.1111/1751-7915.12105

25. Ren J, Zhao CZ, Zhao XW et al (2020) Fractal characteristics of Agriophyllum squarrosum roots in desert-oasis ecotone in Jinta County, Gansu Province. Acta Ecol Sin, 40(15):5298-5305. https://doi.org /10.5846/stxb201904080682 
26. Rossi L, Francini A, Minnocci A, Sebastiani L (2015) Salt stress modifies apoplastic barriers in olive (Oleaeuropaea L.): a comparison between a salt-tolerant and a salt-sensitive cultivar. Sci Hortic 192:38-46. https://doi.org/10.1016/j.scienta.2015.05.023

27. Rubio G, Walk T, Ge Z et al (2001) Root gravitropism and below-ground competition among neighbouring plants: a modelling approach. Ann Bot 88:929-940. https://doi.org/10.1006/anbo.2001.1530

28. Shao HBo, Cui BS, Bai JH (2012) Wetland Ecology in China. CLEAN - Soil Air Water 40(10):10091010. https://doi.org/10.1002/clen.201270003

29. Shan LS, Li Y, Ren W et al (2013) Root architecture of two desert plants in central Hexi Corridor of Northwest China. Chin J Appl Ecol 24: 25-31. https://doi.org /10.13287/j.1001-9332.2013.0152

30. Shi SB, Shang YX, Shi R, Zhang B (2012) Responses of PSIl photochemistry efficiency and photosynthetic pigments of Saussurea superba to short-term UV-B-supplementation. Chinese Journal of Plant Ecology 36:420-430. https://doi.org/10.3724/SP.J.1258.2012.00420

31. Song QH, Zhao CZ, Shi YC et al (2015) Fractal root system of Melica przewalskyi along different aspect in degraded grassland. Chinese Journal of Plant Ecology 39:816-824. https://doi.org/10.17521/cjpe.2015.0078

32. Tatsumi J (2001) Fractal geometry of root system morphology: fractal dimension and multifractals. In: Proc. 6th Symp. Int. Soc. Root Res., Nagoya, Japan, November 11-15, pp. 24-25

33. Tan J, Ben-Gal A, Shtein I et al (2020) Root structural plasticity enhances salt tolerance in mature olives. Environmental Experimental Botany $104224 \mathrm{https} / / /$ doi.org /10.1016/j.envexpbot.2020.104224

34. Van Dusschoten D, Metzner R, Kochs J et al (2016) Quantitative 3D Analysis of Plant Roots growing in Soil using Magnetic Resonance Imaging. Plant Physiology, pp.01388.2015. https://doi.org/10.1104/pp.15.01388

35. Walk TC, van Erp EV, Lynch JP (2004) Modelling applicability of fractal analysis to efficiency of soil exploration by roots. Ann Bot 94(1):119-128. https://doi.org/10.1093/aob/mch116

36. Wang H, Siopongco J, Wade LJ, Yamauchi A (2009) Fractal analysis on root systems of rice plants in response to drought stress. Environ Exp Bot 65(2-3):338-344. https://doi.org/10.1016/j.envexpbot.2008.10.002

37. Wang T, Hu J, Wang R et al (2018) Tolerance and resistance facilitate the invasion success of Alternanthera philoxeroides in disturbed habitats: A reconsideration of the disturbance hypothesis in the light of phenotypic variation. Environ Exp Bot 153:135-142. https://doi.org/10.1016/j.envexpbot.2018.05.011

38. Wang YF, Liu QQ, Pei ZY, Li HY (2012) Correlation between altitude and reproductive allocation in three Saussurea species on China's Qinghai-Tibetan Plateau. Chinese Journal of Plant Ecology 36:39-46. https://doi.org/10.3724/SP.J.1258.2012.00039

39. Wang W, Ding GD, White $P$ et al (2019) Mapping and cloning of quantitative trait loci for phosphorus efficiency in crops: opportunities and challenges. Plant Soil 439:91-112. 
https://doi.org/10.1007/s11104-018-3706-6

40. Warren JM, Hanson PJ, Iversen CM et al (2014) Root structural and functional dynamics in terrestrial biosphere models - evaluation and recommendations. New Phytologist 205(1): 59-78. https://doi.org /10.1111/nph.13034

41. Yang XL, Zhang XM, Li YL, Zhang YL (2015) Analysis and estimation of root architecture in the hinterland of Taklimakan desert base on the fractal theory. Journal of Arid Land Resources and Environment 29(8): 145-150. . Jalre. 2015. 272

42. Yang XL, Zhang XM, Li YL et al (2009) Root fractal characteristics at the hinterland of Taklimakan Desert. Arid Land Geography 32(2):249-254. https://doi.org/10.3969/j.issn.1008-2301.2010.02.001

\section{Figures}

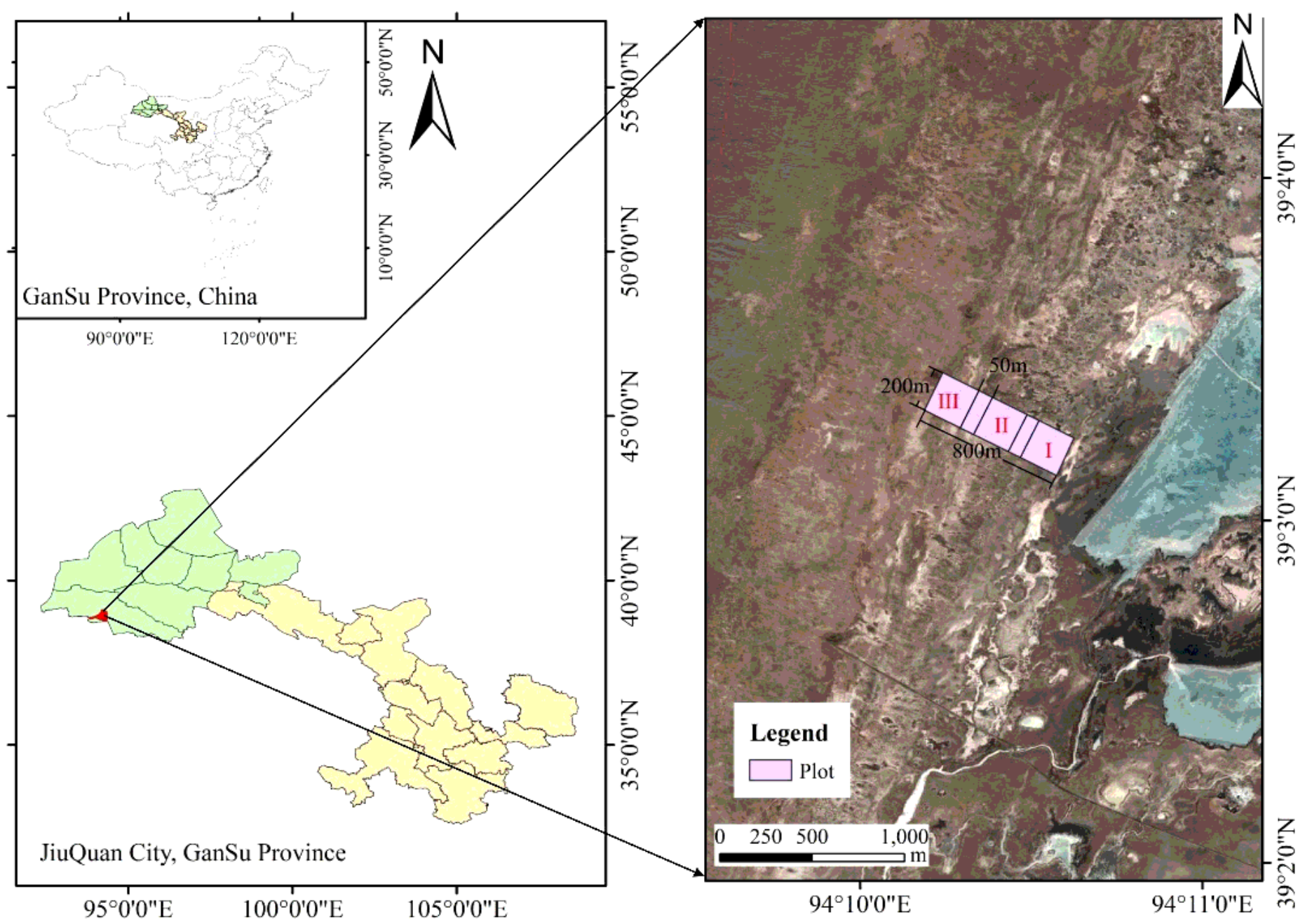

\section{Figure 1}

Study area and locations of measured plots. Note: The designations employed and the presentation of the material on this map do not imply the expression of any opinion whatsoever on the part of Research 
Square concerning the legal status of any country, territory, city or area or of its authorities, or concerning the delimitation of its frontiers or boundaries. This map has been provided by the authors.
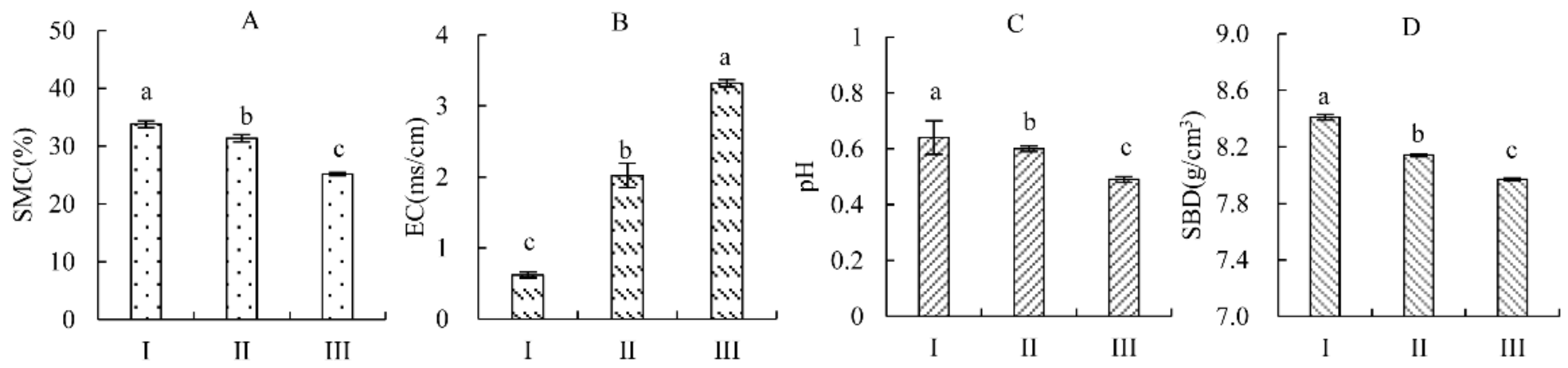

Plot

Figure 2

The soil characteristics of Saussurea salsa in each plot. I, the Near water area, II, the Middle water, area, III, the Far water area. Different lowercase letters indicate significant differences among plots $(P<0.05)$. SMC, EC, SBD....see table 1.
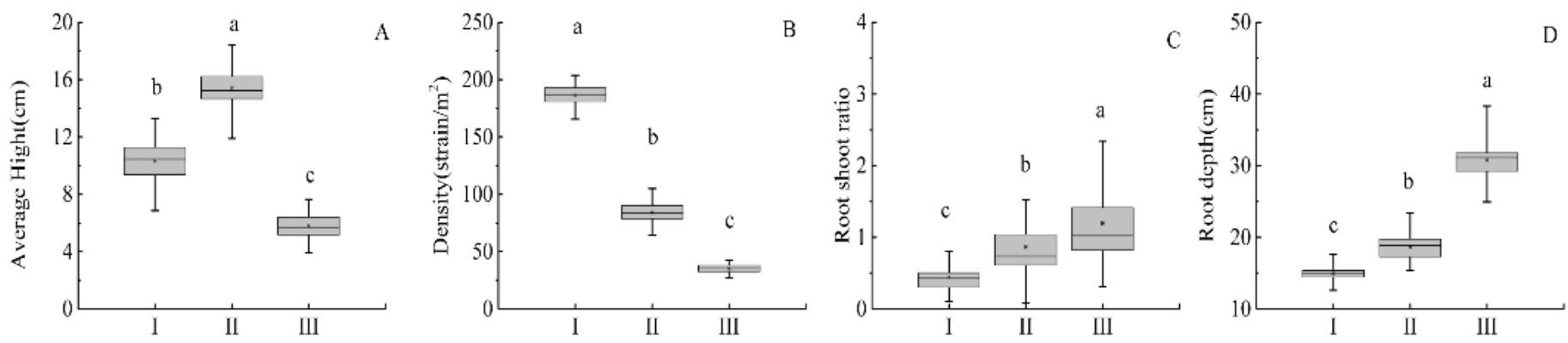

Plot

\section{Figure 3}

The population characteristics of Saussurea salsa in each plot. I, the Near water area, II, the Middle water, area, III, the Far water area. Different lowercase letters indicate significant differences among plots $(\mathrm{P}<$ $0.05)$. 


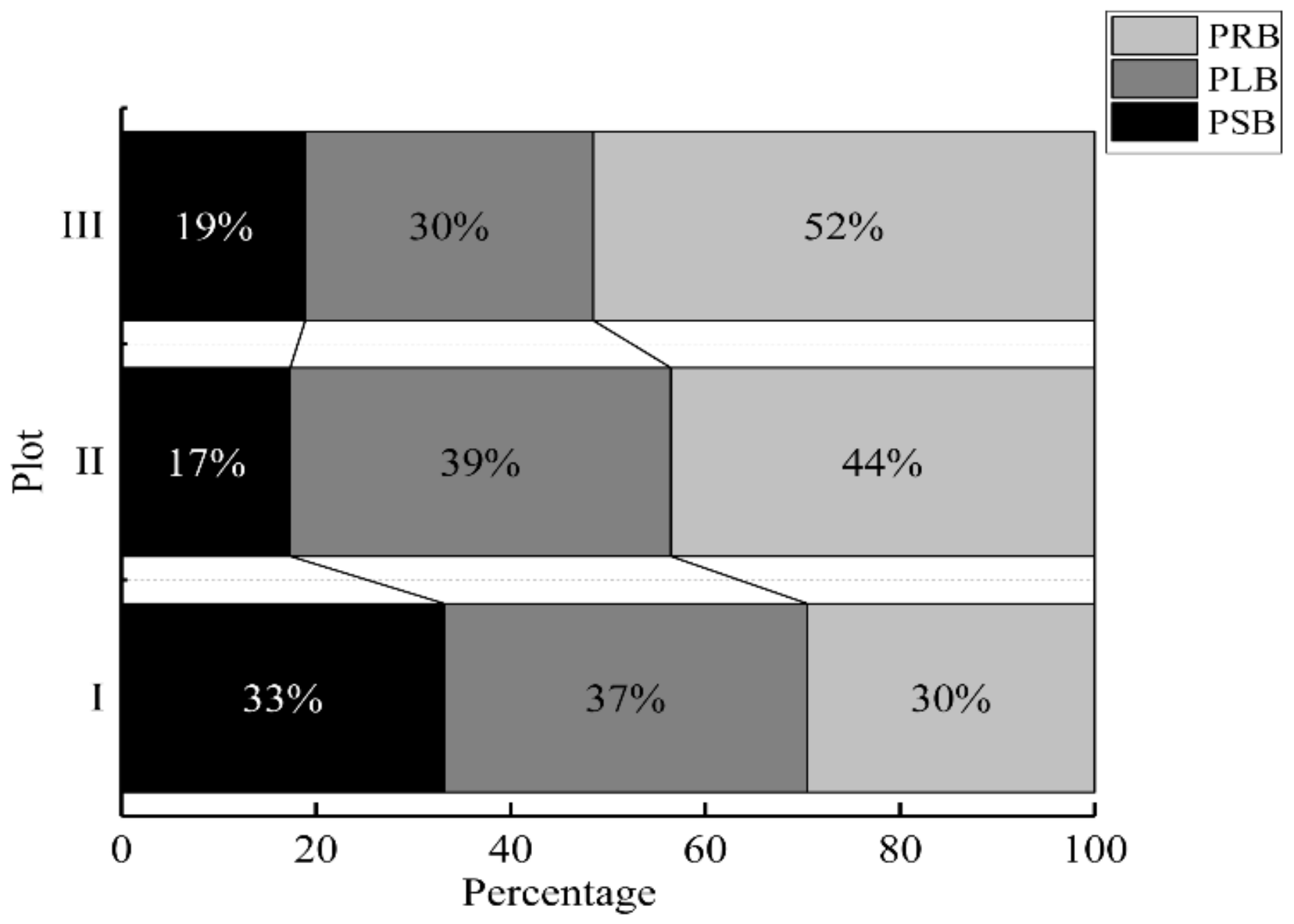

Figure 4

Comparisons of stem biomass fraction, leaf biomass fraction and root biomass fraction under different plots of Saussurea salsa. I, the Near water area, II, the Middle water, area, III, the Far water area. Psb, the stem biomass percentage, $\mathrm{Plb}$, the leaf biomass percentage, Prb, the root biomass percentage. 


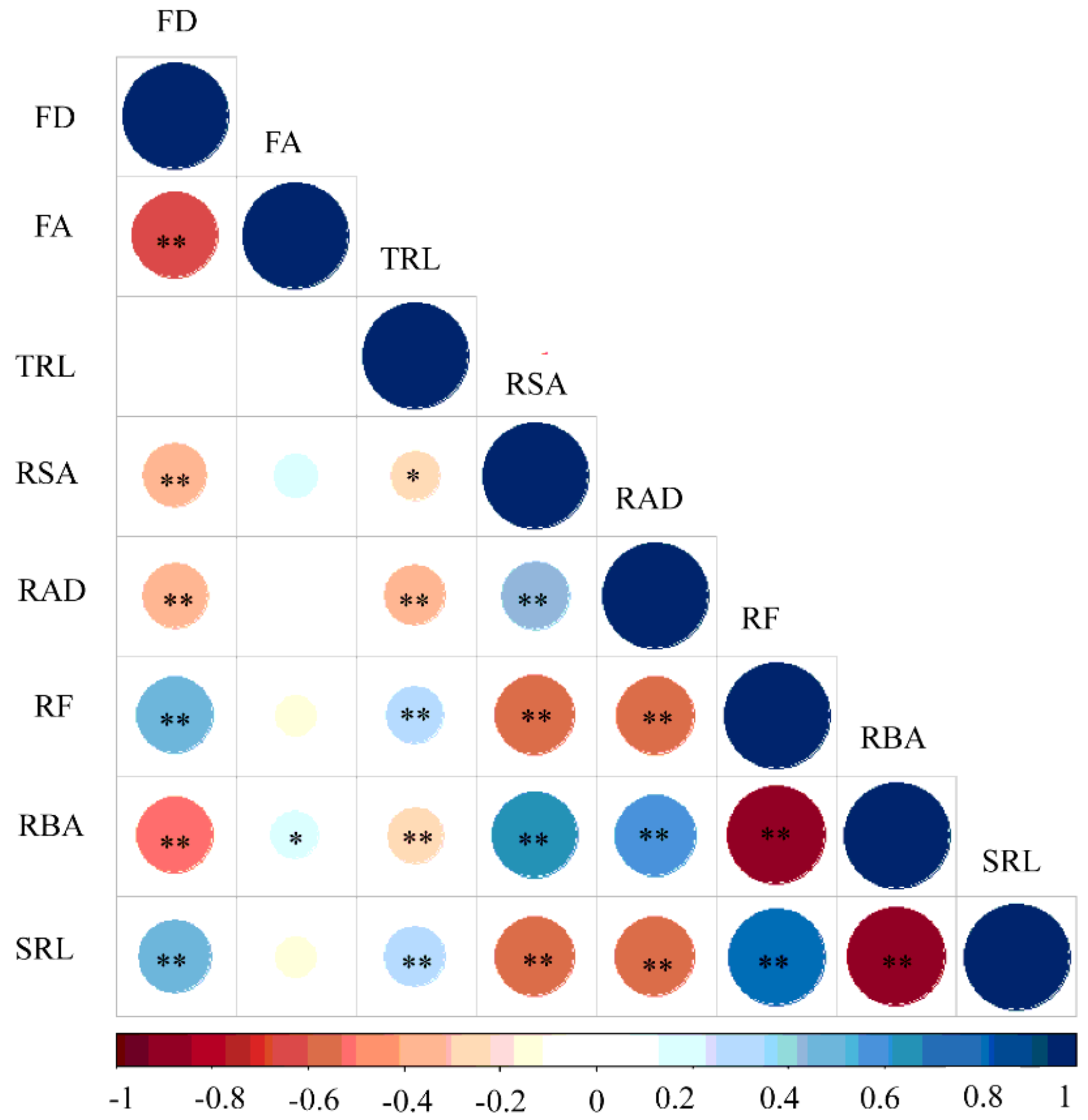

Figure 5

The Correlation analysis of root geometric characteristics and fractal structural parameters of Saussurea salsa. ${ }^{*} p<0.05$ (bilateral); ${ }^{*} p<0.01$ (bilateral). For definition of the parameter abbreviations see Table 1. 

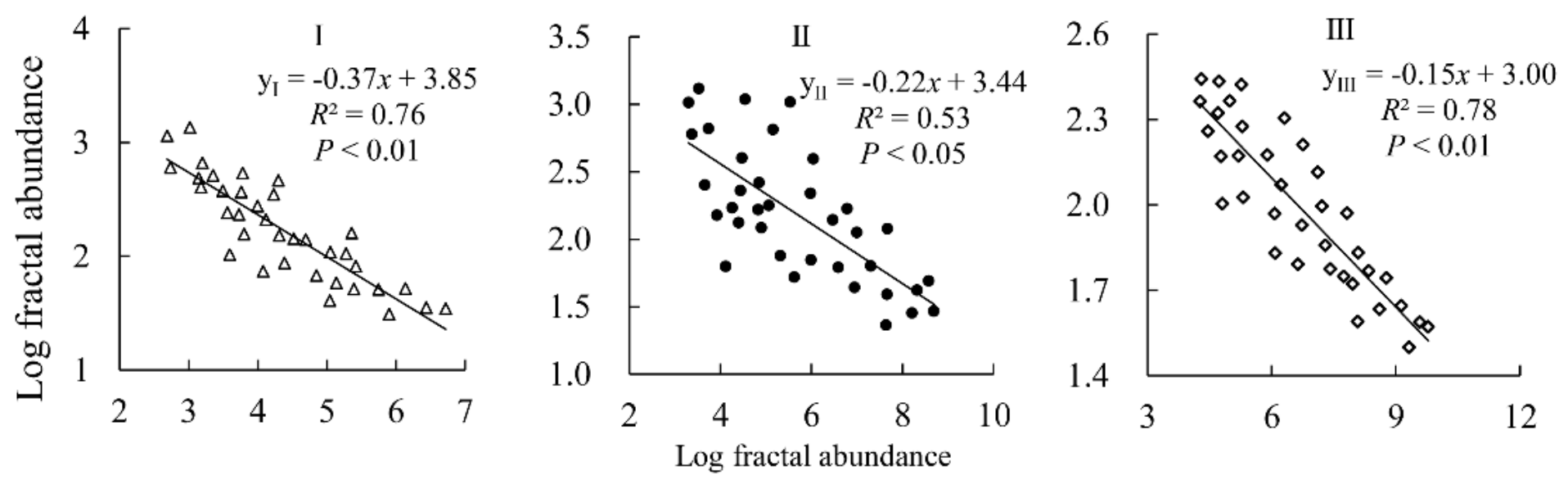

\section{Figure 6}

The correlation between fractal dimension and fractal abundance of Saussurea salsa. I, the Near water area, II, the Middle water, area, III, the Far water area.

\section{Supplementary Files}

This is a list of supplementary files associated with this preprint. Click to download.

- STable1.xlsx

- STable2.xIsx

- STable3.xlsx 